\title{
BMJ Open Incidence of stroke, transient ischaemic attack and determinants of poststroke mortality among immigrants in Denmark, 2004-2018: a population- based cohort study
}

$\overline{\text { George Frederick Mkoma (i) , }{ }^{1} \text { Søren Paaske Johnsen, }{ }^{2} \text { Helle Klingenberg Iversen, }{ }^{3}}$ Grethe Andersen, ${ }^{4}$ Marie Norredam ${ }^{1,5}$

To cite: Mkoma GF, Johnsen SP, Iversen $\mathrm{HK}$, et al. Incidence of stroke, transient ischaemic attack and determinants of poststroke mortality among immigrants in Denmark, 2004-2018: a populationbased cohort study. BMJ Open 2021;11:e049347. doi:10.1136/ bmjopen-2021-049347

- Prepublication history and additional supplemental material for this paper are available online. To view these files, please visit the journal online (http://dx.doi.org/10.1136/ bmjopen-2021-049347).

Received 21 January 2021 Accepted 04 October 2021
Check for updates

(C) Author(s) (or their employer(s)) 2021. Re-use permitted under CC BY-NC. No commercial re-use. See rights and permissions. Published by BMJ.

For numbered affiliations see end of article.

Correspondence to Dr George Frederick Mkoma; george.mkoma@sund.ku.dk

\section{ABSTRACT}

Objective Using recent registry data, we aimed to quantify the incidence of stroke and transient ischaemic attack (TIA) and to examine factors influencing the risk of poststroke mortality among immigrants compared with Danish-born individuals.

Design Population-based cohort study between 2004 and 2018. We estimated age-standardised incidence rate ratios (IRR) of stroke, stroke types and TIA for each ethnic group using Danish-born individuals as the reference by direct method of standardisation. We calculated the risk of poststroke mortality using Cox proportional hazard regression. Setting The study was conducted using Danish nationwide registers.

Participants All cases of first-ever stroke and TIA by country of origin $(n=132936)$ were included.

Results Overall, Western immigrants (IRR=2.25; 95\% $\mathrm{Cl} 2.20$ to 2.31) and non-Western immigrants (IRR=1.37; $95 \% \mathrm{Cl} 1.30$ to 1.44) had a higher risk of stroke than Danish-born individuals. The risk of TIA was higher in Western immigrants (IRR=2.08; 95\% Cl 1.93 to 2.23) followed by non-Western immigrants (IRR $=1.45 ; 95 \% \mathrm{Cl}$ 1.27 to 1.63) than in Danish-born individuals. All-cause 1-year mortality hazard was higher but not significantly different in non-Western men (adjusted $\mathrm{HR}=1.38$; 95\% Cl 0.92 to 2.08) compared with Danish-born men and additional adjustment for comorbidities reduced the HR to 0.85 (0.51 to 1.40) among ischaemic stroke cases. Among intracerebral haemorrhage cases, the adjusted mortality hazard was decreased in Western men (from HR of $1.76 ; 95 \% \mathrm{Cl} 1.09$ to 2.85 to HR of $1.30 ; 95 \%$ Cl 0.80 to 2.11) compared with Danish-born men after adjustment for stroke severity. Immigrants with $\leq 15$ years of residence had a lower poststroke mortality hazard than Danish-born individuals after additional adjustment for sociodemographic factors ( $\mathrm{HR}=0.36$; $95 \% \mathrm{Cl} 0.14$ to 0.91).

Conclusions The age-standardised risk of stroke and TIA was significantly higher among the majority of immigrants than Danish-born individuals. Interventions that reduce the burden of comorbidities, improve acute stroke care and target sociodemographic factors may address the higher risk of poststroke mortality among immigrants.

\section{STRENGTHS AND LIMITATIONS OF THIS STUDY}

$\Rightarrow$ The strength of this study is that it included all patients with first-ever stroke and transient ischaemic attack in Denmark and a long follow-up.

$\Rightarrow$ The utilised data set enabled analyses of risk of stroke and mortality according to stroke type, sex and country of origin.

$\Rightarrow$ Lack of individual-level data on comorbidities and sociodemographic factors from the general population could not allow adjustment in the incidence analysis.

$\Rightarrow$ This study has not considered the impact of cholesterol, physical activity, diet, alcohol use and psychosocial factors on the risk of poststroke mortality among immigrants.

\section{INTRODUCTION}

Immigrants make up a growing proportion of European populations, and in Denmark, they accounted for $10 \%$ of the population by 1 January $2019 .{ }^{1}$ As the number of international migrants continues to increase in Denmark and elsewhere, understanding migrant health has become an important public health agenda.

Stroke affected 12283 individuals in Denmark in 2019 and is considered a leading cause of disability and death among adults. ${ }^{2}$ Several studies have reported ethnic variations in stroke incidence and mortality. ${ }^{3-7}$ For example, a Dutch study found that stroke incidence was higher in Surinamese, while lower in Moroccans than in ethnic Dutch. ${ }^{5} \mathrm{~A}$ Scottish study reported that stroke mortality rates were higher for people originating from Africa and Pakistan, while lower in Chinese immigrants than in White Scottish. ${ }^{6}$ Ethnic variations in stroke mortality have also been demonstrated in England, Wales and the USA. $^{8} 9$ These studies, however, examined 
stroke incidence and mortality using data collected before 2010. In addition, data on transient ischaemic attack (TIA) among immigrants are also lacking in populationbased settings.

Risk factors for stroke are well established. ${ }^{1011}$ Studies show that immigrants are at higher risk of diabetes ${ }^{12}$ and multimorbidity ${ }^{13}$ and are less likely to engage in healthy lifestyle behaviours than non-immigrants. ${ }^{14} 15$ Migration is increasingly regarded as a social determinant of health, and the potential mechanism associated with morbidity and mortality among immigrants may also be attributed to socioeconomic conditions. ${ }^{16}$ However, little is known about poststroke mortality among immigrants when factors like comorbidities, stroke severity, thrombolysis, income, education, employment, marital status and duration of residence are taken into account. Addressing this gap would both provide a better understanding of the causal links between ethnicity and poststroke mortality and would also help tailor preventive policies as well as diagnostics and treatment efforts to patients' needs. Using a nationwide sample, we aimed to quantify the incidence of stroke (including stroke types) and TIA and to examine factors influencing the risk of poststroke mortality among immigrants compared with Danishborn individuals using recent registry data.

\section{METHODS \\ Design}

We obtained data from the Danish Stroke Registry (DSR), the National Patient Registry (NPR), the Cause of Death Register and the Registers at Statistics Denmark. Since 2003, all hospitals in Denmark treating patients with acute stroke and TIA are required by law to register data into the DSR. More detailed information about the DSR has been published elsewhere. ${ }^{17}$ All diagnoses are classified in accordance with the WHO's International Classification of Diseases (ICD) system, 10th revision (ICD 10). For a detailed description of variables and their sources, see online supplemental table S1.

We included a population of men and women aged 18 to 95 years based on the entire Danish population between 1 January 2004 and 31 December 2018. First, we identified the number of individuals (in age and sex groups) in the population for each year and subsequently extracted individuals with first-ever stroke (ischaemic stroke (IS), intracerebral haemorrhage (ICH) and unspecified stroke) and TIA. Second, we created a cohort of individuals with first-ever stroke starting from 1 January 2004. Individuals were followed from the first-ever stroke to the following events: (i) poststroke death or (ii) study end (31 December 2018). Subjects were censored at the time of emigration or study end, whichever came first. Patients with a previous diagnosis of stroke or TIA were excluded. In the present study, all data were obtained by linkage using the unique 10-digit personal identification number assigned to all residents in Denmark.

\section{Country of origin}

The main exposure was country of origin, which we used to construct the population of immigrants. According to Statistics Denmark, immigrants are defined as "persons born abroad whose parents are both (or one of them if there is no available information on the other parent) foreign citizens or were both born abroad ${ }^{18}$ Descendants are defined by the same criteria except they are born in Denmark. We included immigrants only and excluded their descendants due to small numbers. Major countries of origin among immigrants were identified and selected based on the largest person years at risk during the study period. The following immigrant populations were included in the study: Turkish, Polish, German, Norwegian, Iraqi, Swedish, Pakistani, Ex-Yugoslavian and Iranian. Furthermore, Turkish, Iraqi, Pakistani, Ex-Yugoslavian and Iranian were classified as non-Western immigrants, whereas German, Norwegian, Swedish and Polish were classified as Western immigrants according to Statistics Denmark's classification system. ${ }^{18}$ Danish-born individuals were used as the reference.

\section{Outcome variables}

Our primary outcomes were stroke (IS [ICD 10, I63], ICH [ICD 10, I61] and unspecified stroke [ICD 10, I64]) and TIA (ICD 10, G45). Stroke was defined as total absolute number of events for IS, ICH and unspecified stroke. Stroke types were IS, ICH and unspecified stroke. The number of unspecified strokes per immigrants was low and hence not presented as an individual category in accordance with Statistics Denmark's data confidentiality policy. ${ }^{19}$ Secondary outcome was poststroke mortality among IS and ICH cases. Poststroke mortality in three different periods were included: short-term (from admission to 1 year), 3-year (from admission to 3 years) and long-term (from admission to 5 years). Based on the priori hypothesis that short-term clinical outcomes might be related to the severity of stroke symptoms and differences in care after stroke, we therefore mostly present 1-year poststroke mortality.

\section{Covariates}

We used age and sex as covariates when calculating the incidence of stroke, stroke types and TIA among immigrants compared with Danish-born individuals. Covariates for the risk of poststroke mortality included age at stroke, age at immigration, sex, smoking, comorbidities, stroke severity, thrombolytic or endovascular therapy, education, employment status, income, marital status and duration of residence. Education was grouped into three levels: low, medium and high according to the International Standard Classification of Education (ISCED). Income was categorised as low, middle and high. We classified employment status as employed, unemployed, pensioner and other. Marital status was grouped as 
cohabiting, single and other. Body Mass Index was categorised into four levels: underweight, normal weight, overweight and obesity using the WHO's cut-off values. ${ }^{20}$ Smoker, ex-smoker and never smoker were the categories for smoking status. Stroke severity was classified into the following: very severe, severe, moderate and mild stroke according to the Scandinavian Stroke Scale score. We created a composite variable for thrombolytic and endovascular therapy and classified it as yes and no. Yes meant that patients received either thrombolytic or endovascular therapy and no meant that patients did not receive either of the therapies. Comorbidities were defined as any of the following diagnoses accompanying the stroke or TIA diagnosis: hypertension (ICD 10, I10), acute myocardial infarction (ICD 10, I21), atrial fibrillation (ICD 10, I48), diabetes (ICD 10, E10-E14) and peripheral artery disease (ICD 10, I73).

\section{Statistical analyses}

We calculated age-standardised incidence rates (IR) of stroke, stroke types and TIA per 100000 person years stratified by country of origin and sex using the 2004 Danish population as reference standard by direct method of standardisation. In addition, we estimated age-standardised incidence rate ratios (IRR) of stroke, stroke types and TIA with $95 \%$ CIs for each ethnic group using Danish-born individuals as a reference. We present both country classification and country-specific IRR estimates. We conducted Cox proportional hazard regression to estimate the risk of short-term and long-term poststroke mortality among immigrants compared with Danish-born individuals. The HR estimates were limited to country classification due to a small number of outcome events in the analyses of poststroke mortality. We checked for proportional hazard assumptions using Schoenfeld's test and its residuals. Covariates such as employment status and income displayed non-proportional hazards. Acute myocardial infarction, atrial fibrillation as well as smoking also showed signs of non-proportional hazards. Thus, these covariates were stratified in the models where applicable. Model 1 was adjusted for age. Model 2 was additionally adjusted for smoking, acute myocardial infarction, diabetes, hypertension, atrial fibrillation and peripheral artery disease. Model 3 was further adjusted for stroke severity and thrombolytic or endovascular therapy (only for IS). Model 4 was the same as model 3 but adjusted for marital status, education, employment status and income. We examined whether age at immigration and duration of residence ( $\leq 15$ years or $>15$ years in Denmark) influenced the risk of poststroke mortality since these factors relate to acculturation and socioeconomic status and may impact acute stroke care as well as transition of care after stroke. We also evaluated the risk of poststroke mortality using data from 2010 onwards in a sensitivity analysis. All analyses were performed in $\mathrm{R}$ statistical software (V.4.0.2 and V.3.3.3).

\section{Patient and public involvement}

Patients and the public were not involved in the design, conduct, reporting or dissemination of the present study.

\section{RESULTS}

\section{Baseline characteristics}

Among the 132936 of the included patients with acute stroke and TIA, 2922 were immigrants and 130014 were Danish-born individuals between 2004 and 2018 period. Overall, non-Western immigrants were younger at stroke and TIA diagnoses, more likely to be unemployed and more likely to be cohabiting than Danish-born individuals. Hypertension was the most common comorbidity in this nationwide sample, followed by diabetes in non-Western immigrants and atrial fibrillation in Western immigrants. Smoking was more frequent among Ex-Yugoslavians. Iranian and Pakistani were the least likely of all ethnic groups to be treated with thrombolysis. The majority of the study participants had mild stroke (table 1).

\section{Risk of stroke and TIA}

For absolute numbers, age-standardised IRs of stroke, stroke types and TIA, see online supplemental tables S2 and S3. TIA data were available from 2013 onwards. Overall, Western immigrants (age-standardised IRR $=2.25$; 95\% CI 2.20 to 2.31) and non-Western immigrants (IRR=1.37; 95\% CI 1.30 to 1.44 ) had a higher risk of stroke than Danish-born individuals (online supplemental figure S1). The risk of TIA was highest in Western immigrants (IRR=2.08; 95\% CI 1.93 to 2.23 ) followed by non-Western immigrants (IRR $=1.45 ; 95 \%$ CI 1.27 to 1.63 ). For the risk of IS and ICH, similar results were observed among immigrants compared with Danish-born individuals (online supplemental figure S2).

Men originating from Poland, followed by men originating from Germany, Sweden, Norway, Ex-Yugoslavia and Pakistan had a higher risk of stroke and TIA than Danishborn men. Among women, the highest risk of stroke and TIA was observed in individuals originating from Pakistan; followed by Germany, Iran, Iraq and Ex-Yugoslavia (figure 1). We observed similar trends in country-specific data for risk of IS and ICH among immigrants compared with Danish-born individuals (figure 2).

\section{Determinants of post-stroke mortality}

The all-cause 1-year mortality hazard was higher but not significantly different in non-Western men (adjusted $\mathrm{HR}=1.38$; $95 \%$ CI 0.92 to 2.08) compared with Danishborn men and additional adjustment for comorbidities reduced the HR to 0.85 ( 0.51 to 1.40$)$ among IS cases (table 2). The 1-year mortality hazard was reduced to 0.70 in non-Western men (HR=0.70; 95\% CI 0.41 to 1.17 ) after further adjustment for stroke severity and thrombolytic or endovascular therapy. Among ICH cases, the adjusted mortality hazard was decreased in Western men (from 


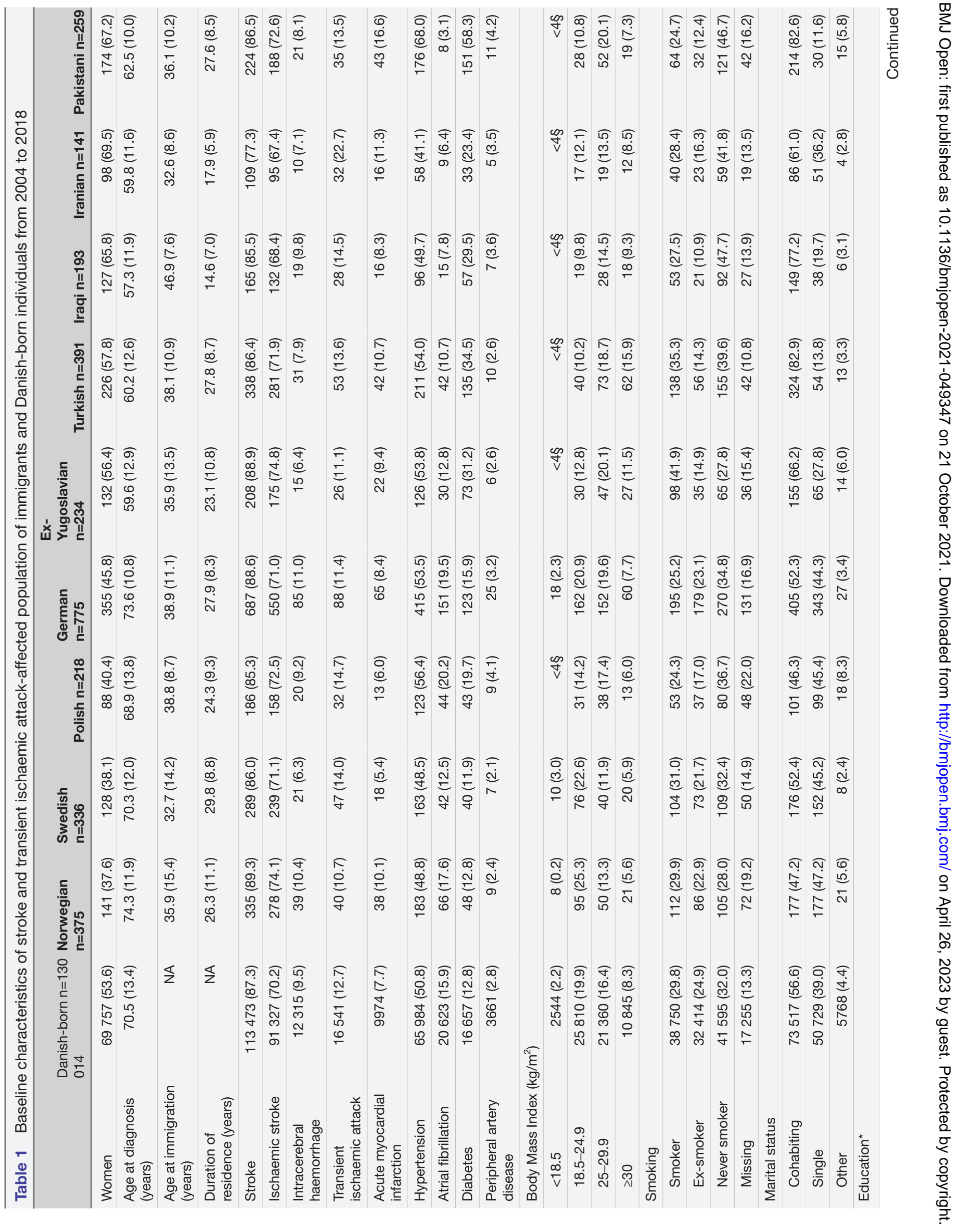




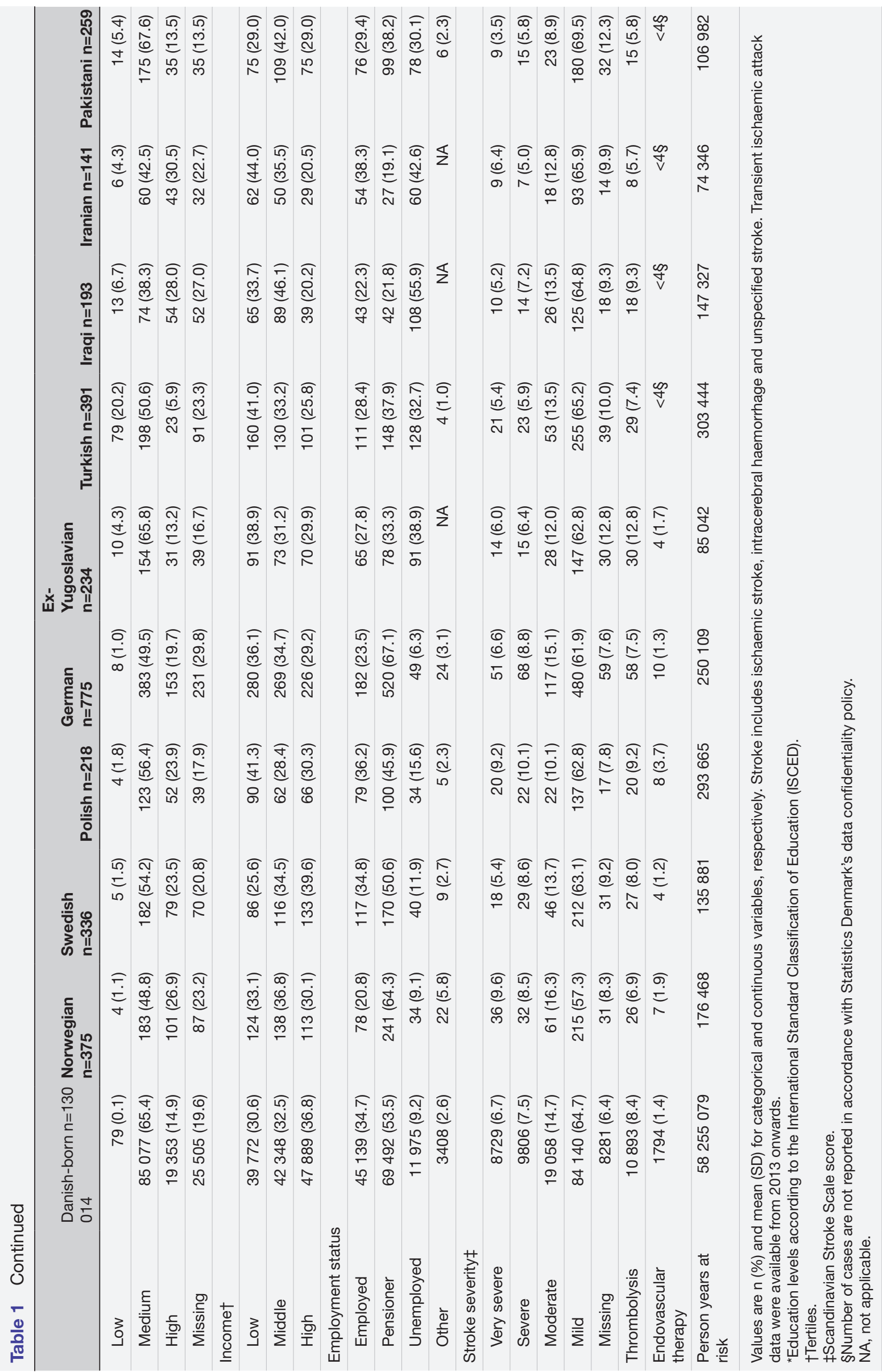




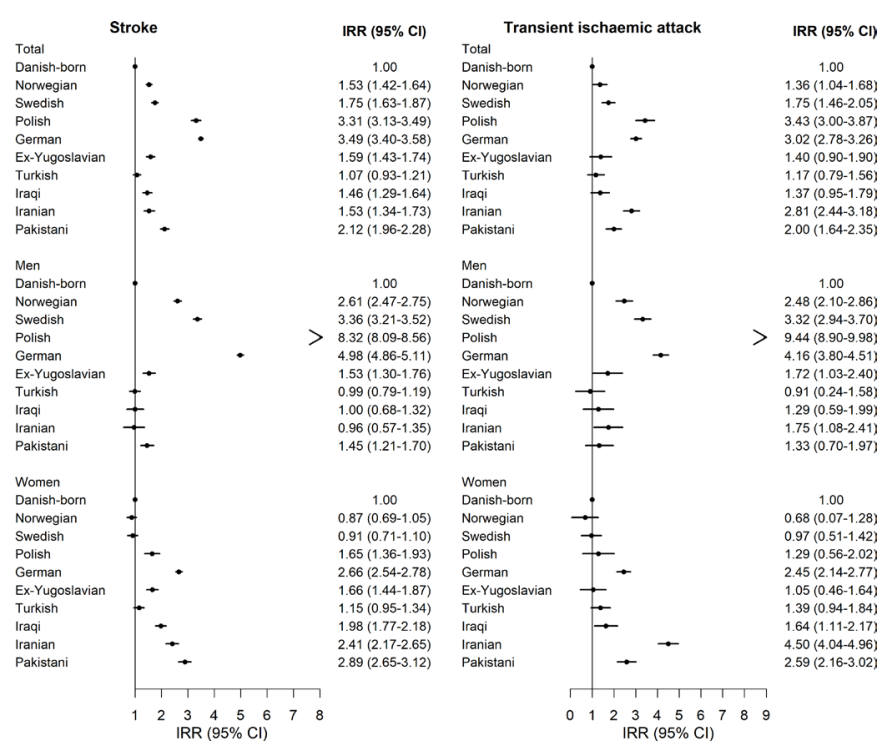

Figure 1 Incidence rate ratio (IRR) of stroke and transient ischaemic attack in immigrants compared with Danish-born individuals.

HR of $1.76 ; 95 \%$ CI 1.09 to 2.85 to HR of $1.30 ; 95 \%$ CI 0.80 to 2.11 ) compared with Danish-born men after additional adjustment for stroke severity. A similar trend was observed in non-Western men for the risk of post-ICH mortality. In the fully adjusted model (including sociodemographic factors), the poststroke mortality hazard was further decreased, notably among non-Western individuals; however, it was non-significant compared with Danish-born individuals. Among female IS and ICH cases, we found no significant difference in all-cause 1-year mortality hazard among Western and non-Western women compared with Danish-born women. Further analysis showed that immigrants with shorter residence ( $\leq 15$ years in Denmark) had significantly lower 1-year

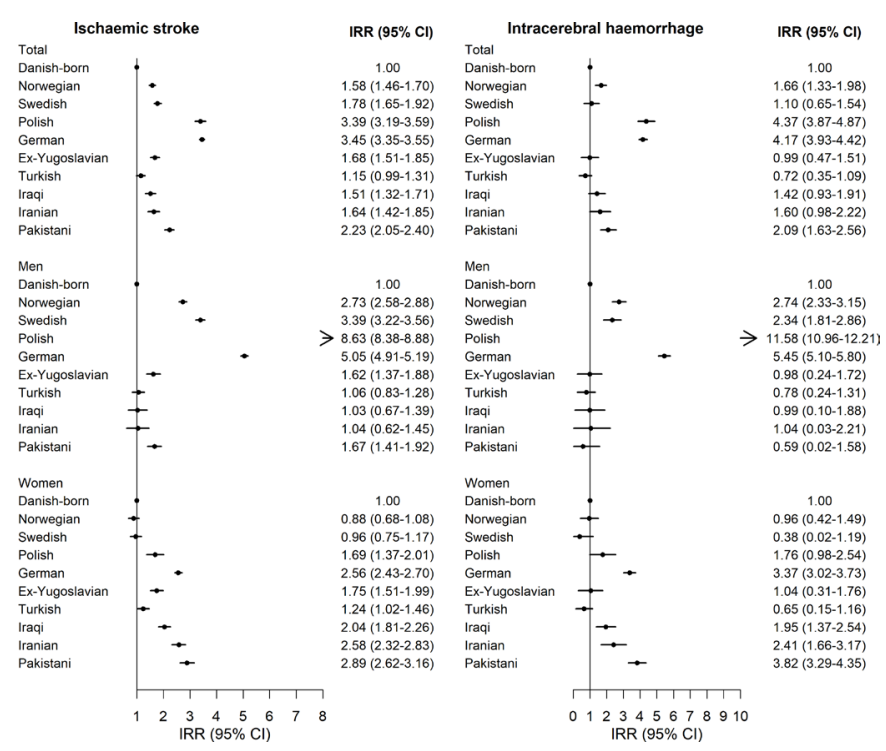

Figure 2 Incidence rate ratio (IRR) of ischaemic stroke and intracerebral haemorrhage in immigrants compared with Danish-born individuals. poststroke mortality hazard than Danish-born individuals after additional adjustment for sociodemographic factors ( $\mathrm{HR}=0.36 ; 95 \%$ CI 0.14 to 0.91 ) (figure 3 and online supplemental table S4). However, the lower 1-year mortality hazard disappeared with longer residence $(>15$ years in Denmark) (HR=0.97; 95\% CI 0.73 to 1.29$)$. The 3-year and 5-year mortality HRs by ethnic group are shown in online supplemental table S5. Compared with Danishborn men, Western men had an increased risk of all-cause 5-year mortality (HR=1.58; 95\% CI 1.01 to 2.48 ) following ICH after adjustment for all confounders.

Sensitivity analysis yielded results similar to those of the main analysis, except that immigrants who arrived at 18-24 years of age had a reduced 1-year poststroke mortality hazard compared with Danish-born individuals (online supplemental tables S6 and S7). Impact of comorbidities on all-cause 1-year mortality by ethnic group is shown in online supplemental table S8.

\section{DISCUSSION}

This population-based cohort study demonstrates that the risk of stroke and TIA was significantly elevated for both sexes among the majority of immigrants compared with the Danish-born population. We found the highest risk of stroke and TIA among men originating from Poland, Germany, Sweden, Norway, Ex-Yugoslavia and Pakistan. Among women, the highest risk of stroke and TIA was observed in individuals originating from Pakistan, Germany, Iran, Iraq and Ex-Yugoslavia. Furthermore, the 1-year and 3-year poststroke mortality risk did not differ between immigrants and Danish-born individuals. However, the 5-year mortality risk was found to be higher in Western men than in Danish-born men following ICH.

Our findings are concordant with those of a Norwegian study reporting a higher risk of stroke among South Asians, particularly Pakistani, than among Norwegian-born individuals. ${ }^{3}$ Few population-based studies have reported on firstever TIA incidence. Moreover, they did not use a nationwide sample, and ethnicity was not their focus. ${ }^{21} 22$ The Global Burden of Disease study recommends generating estimates for TIA $;{ }^{23}$ and improvements in our understanding of the mechanisms causing the incidence of stroke to rise are essential for planning prevention strategies. The present study provides insight into the hitherto sparsely studied incidence of TIA among immigrants. Regarding stroke types, in general, we found a higher risk of IS and ICH among the majority of immigrants than Danish-born individuals. In contrast, we found the risk of ICH among Turkish women to be similar to that of Danish-born women. A Dutch study demonstrated a similar pattern for the risk of ICH among Turkish women. ${ }^{5}$

Non-Western immigrants were younger at stroke diagnosis than Western immigrants and Danish-born individuals. Our results clearly corroborate previous studies in the UK and the USA reporting that Black British ${ }^{24}$ and Asian Americans ${ }^{25}$ experience early onset of stroke. A Danish study on uptake of cardiac rehabilitation and 
Table 2 All-cause 1-year mortality hazard ratios (HRs) in immigrants compared with Danish-born individuals

\begin{tabular}{|c|c|c|c|c|c|c|}
\hline & Deaths & Unadjusted & Model 1 & Model 2 & Model 3 & Model 4 \\
\hline & $\mathbf{N}$ & HR (95\% Cl) & HR (95\% Cl) & HR (95\% Cl) & HR (95\% Cl) & HR (95\% Cl) \\
\hline \multicolumn{7}{|l|}{ Ischaemic stroke } \\
\hline \multicolumn{7}{|l|}{ Men } \\
\hline Danish-born (ref) & 6152 & 1.00 & 1.00 & 1.00 & 1.00 & 1.00 \\
\hline Western* & 115 & $1.12(0.93$ to 1.34$)$ & $1.10(0.92$ to 1.33$)$ & $1.01(0.80$ to 1.26$)$ & $1.00(0.80$ to 1.27$)$ & 1.05 (0.81 to 1.37$)$ \\
\hline Non-Western† & 23 & 1.13 (0.75 to 1.69$)$ & 1.38 (0.92 to 2.08) & 0.85 (0.51 to 1.40$)$ & $0.70(0.41$ to 1.17$)$ & 0.55 (0.28 to 1.08$)$ \\
\hline \multicolumn{7}{|l|}{ Women } \\
\hline Danish-born (ref) & 6138 & 1.00 & 1.00 & 1.00 & 1.00 & 1.00 \\
\hline Western* & 51 & $0.86(0.65$ to 1.14$)$ & $0.92(0.70$ to 1.21$)$ & 0.86 (0.60 to 1.22$)$ & $0.79(0.54$ to 1.14$)$ & 0.64 (0.38 to 1.07$)$ \\
\hline Non-Western† & 32 & $0.89(0.63$ to 1.26$)$ & 1.01 (0.71 to 1.43$)$ & 0.84 (0.53 to 1.33$)$ & $0.83(0.52$ to 1.34$)$ & 0.77 (0.45 to 1.32$)$ \\
\hline \multicolumn{7}{|c|}{ Intracerebral haemorrhage } \\
\hline \multicolumn{7}{|l|}{ Men } \\
\hline Danish-born (ref) & 2003 & 1.00 & 1.00 & 1.00 & 1.00 & 1.00 \\
\hline Western* & 30 & $1.46(1.02$ to 2.10$)$ & $1.48(1.03$ to 2.13$)$ & $1.76(1.09$ to 2.85$)$ & $1.30(0.80$ to 2.11$)$ & 1.32 (0.81 to 2.17$)$ \\
\hline Non-Western† & 9 & 1.03 (0.53 to 1.98$)$ & 1.05 (0.54 to 2.05$)$ & 1.27 (0.56 to 2.85 ) & 0.98 (0.43 to 2.22 ) & 1.09 (0.39 to 3.04$)$ \\
\hline \multicolumn{7}{|l|}{ Women } \\
\hline Danish-born (ref) & 2164 & 1.00 & 1.00 & 1.00 & 1.00 & 1.00 \\
\hline Western* & 16 & 0.73 (0.44 to 1.19$)$ & 0.74 (0.45 to 1.20$)$ & 0.80 (0.45 to 1.42$)$ & 0.99 (0.56 to 1.76$)$ & 0.85 (0.43 to 1.68$)$ \\
\hline Non-Western† & 10 & $0.49(0.26$ to 0.91$)$ & $0.53(0.28$ to 0.98$)$ & $0.45(0.20$ to 1.01$)$ & $0.53(0.24$ to 1.19$)$ & $0.49(0.19$ to 1.23$)$ \\
\hline \multicolumn{7}{|c|}{$\begin{array}{l}\text { Model 1: Adjusted for age at stroke. } \\
\text { Model 2: Additionally adjusted for smoking, acute myocardial infarction, diabetes, hypertension, atrial fibrillation and peripheral artery disease. } \\
\text { Model 3: Further adjusted for stroke severity and thrombolytic or endovascular therapy (only for ischaemic stroke). } \\
\text { Model } 4 \text { (Fully adjusted): Model } 3 \text { additionally adjusted for marital status, education, employment status and income. } \\
\text { *Western includes Norwegian, Swedish, Polish and German. } \\
\text { †Non-Western includes Ex-Yugoslavian, Turkish, Iraqi, Iranian and Pakistani. }\end{array}$} \\
\hline
\end{tabular}

preventive medications after acute coronary syndrome showed that non-Western immigrants had a $50 \%$ to $75 \%$ higher risk of discontinuing various preventive medications, which could be seen as one of the possible explanations for early stroke onset in this population. ${ }^{26}$

- Unadjusted

- Adjusted for age and sex

Adjusted for age, sex, marital status, education, employment status and income

Danish-born (ref)

Immigrants (<=15 years of residence)

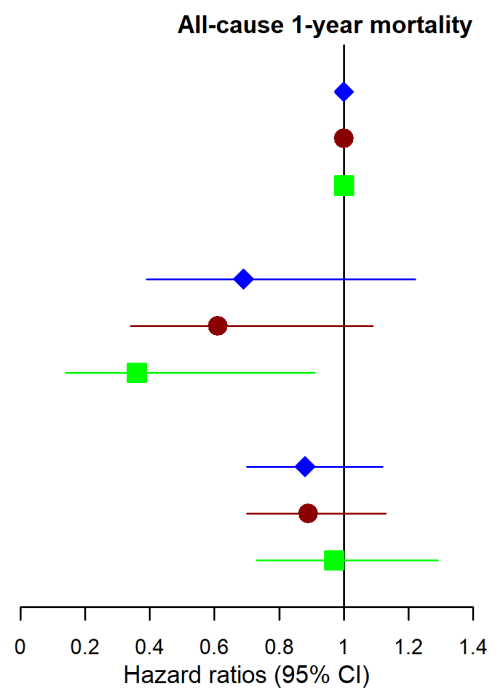

Figure 3 Association between duration of residence and all-cause 1-year mortality.
The higher risk of stroke and TIA among immigrants than among Danish-born individuals may partly be due to the burden of comorbidities, a high smoking rate and poor socioeconomic conditions among immigrants. A study in Denmark reported that non-Western immigrants have a 2.5 times higher risk of diabetes than local-born individuals. ${ }^{12}$ In addition, our data show that Ex-Yugoslavians were more likely to smoke than other ethnic groups. In association with the socioeconomic conditions, previous evidence shows a higher incidence of stroke among immigrants with low income than among those with high income. ${ }^{16}$ Our study also shows that Polish men had an exceptionally higher incidence of stroke and TIA and were more likely to have low income than were other immigrants. The higher incidence of stroke and TIA among immigrants might also be explained by other risk factors for stroke such as psychosocial distress and depressive symptoms. ${ }^{1027} 28$

The patterns of short-term and long-term poststroke mortality appeared to differ among immigrants compared with Danish-born individuals for both sexes and all stroke types. The observed increased risk of poststroke mortality among non-Western men seems to be substantially influenced by comorbidities, stroke severity, thrombolysis and socioeconomic conditions, notably for IS cases. Stroke severity and socioeconomic conditions also affected the risk of poststroke mortality among immigrants of Western origin. We demonstrated an increased risk of long-term 
(5-year) mortality among Western men compared with Danish-born men post-ICH after controlling for a wide range of clinical and sociodemographic factors. Consistent with our findings, a Dutch study reported a higher risk of short-term and long-term poststroke mortality among both Western and non-Western immigrants after controlling for comorbidities. ${ }^{4}$ However, data disaggregated by stroke types, stroke severity, stroke treatment and sociodemographic factors were missing in the Dutch study. Poor healthcare utilisation may contribute to explaining why Western men had a higher risk of long-term poststroke mortality than Danish-born men. ${ }^{26}$ Our data show sex differences in the risk of poststroke mortality among immigrants compared with Danish-born individuals. Previous studies have also reported sex differences in long-term stroke outcomes. ${ }^{29}$ The observed sex differences among immigrants could be related to factors associated with timely admission, access to stroke care and poststroke social conditions. Although immigrants with shorter residence in Denmark had a short-term mortality advantage, we found that those with longer residence had a short-term poststroke mortality risk similar to that of Danish-born individuals. Corroborating evidence has already been established regarding this pattern, which is generally described as the so-called healthy migrant effect. ${ }^{3031}$ It is suggested that migrants might be healthier than the host population at the time of their arrival, but this health advantage diminishes over time. Acculturation and increasing allostatic load are considered to accelerate a negative selection effect, resulting in the loss of an immigrant mortality advantage. ${ }^{31}$

A major strength of our study is the use of national Danish registers, which enabled us to create an entire cohort of patients with acute stroke and a long follow-up. The DSR and the NPR have been reported to have a high level of validity for the majority of principal and secondary diagnoses. ${ }^{32-34}$ In combination with previous literature in increasing stroke awareness, ${ }^{35}$ our findings suggest that reducing the burden of comorbidities, improving acute stroke care and targeting sociodemographic factors could be instrumental in reducing stroke mortality among immigrants. This study unravels previous limitations by including information on a wide range of clinical and sociodemographic factors; however, we cannot exclude the possibility of residual confounding. We acknowledge that the current estimates might be attributed to small sample size, as we observed few deaths among immigrants after ICH. The present study was unable to investigate the impact of cholesterol, physical activity, diet, alcohol use and psychosocial factors. Furthermore, we could not perform stepwise adjustment for incidence analysis due to lack of individual-level data on comorbidities and sociodemographic factors from the general population. Our results underscore the need for further research as immigrants are often exposed to deprived social conditions, which may propagate early stroke onset, encounter problems accessing diagnosis and treatment and ultimately suffer increased mortality.

\section{Author affiliations}

${ }^{1}$ Danish Research Centre for Migration, Ethnicity and Health, Department of Public Health, University of Copenhagen Faculty of Health and Medical Sciences, Copenhagen, Denmark

${ }^{2}$ Danish Centre for Clinical Health Services Research, Department of Clinical Medicine, Aalborg University, Aalborg, Denmark

${ }^{3}$ Stroke Centre Rigshospitalet, Department of Neurology, University of Copenhagen Faculty of Health and Medical Sciences, Copenhagen, Denmark

${ }^{4}$ Danish Stroke Centre, Department of Neurology, Aarhus University Hospital, Aarhus University, Aarhus, Denmark

${ }^{5}$ Department of Infectious Diseases, Hvidovre Hospital, University of Copenhagen Faculty of Health and Medical Sciences, Copenhagen, Denmark

Contributors GFM, SPJ, HKI and MN designed the study and analytical strategy. GFM performed the literature review, analysed cohort data and prepared results. GFM, SPJ, HKI, GA and MN contributed to the interpretation of results. GFM wrote the first draft of the report. All other collaborators commented on the report draft and approved the final text. MN is the study guarantor.

Funding The study was supported by TrygFonden (ID: 126642).

Competing interests None declared.

Patient consent for publication Not required.

Ethics approval The study was approved by the Danish Data Protection Agency, reference number 514-0457/20-3000, and adhered to the World Medical Association's Declaration of Helsinki. In Denmark, no further approval is required regarding registry-based research.

Provenance and peer review Not commissioned; externally peer reviewed.

Data availability statement Data may be obtained from a third party and are not publicly available. Data used in this study are stored at Statistics Denmark, and access can be granted subject to approval by Statistics Denmark. Guidelines on access to registers can be found on Statistics Denmark website via https://www. dst.dk/en/TilSalg/Forskningsservice.

Supplemental material This content has been supplied by the author(s). It has not been vetted by BMJ Publishing Group Limited (BMJ) and may not have been peer-reviewed. Any opinions or recommendations discussed are solely those of the author(s) and are not endorsed by BMJ. BMJ disclaims all liability and responsibility arising from any reliance placed on the content. Where the content includes any translated material, BMJ does not warrant the accuracy and reliability of the translations (including but not limited to local regulations, clinical guidelines, terminology, drug names and drug dosages), and is not responsible for any error and/or omissions arising from translation and adaptation or otherwise.

Open access This is an open access article distributed in accordance with the Creative Commons Attribution Non Commercial (CC BY-NC 4.0) license, which permits others to distribute, remix, adapt, build upon this work non-commercially, and license their derivative works on different terms, provided the original work is properly cited, appropriate credit is given, any changes made indicated, and the use is non-commercial. See: http://creativecommons.org/licenses/by-nc/4.0/.

ORCID iD

George Frederick Mkoma http://orcid.org/0000-0001-8073-3586

\section{REFERENCES}

1 Statistics Denmark. Immigrants in Denmark, 2019. Available: https:// www.dst.dk/Site/Dst/Udgivelser/GetPubFile. aspx? id=29446\&sid= indv2019 [Accessed 20 Dec 2020].

2 Danish Stroke Registry. Annual report, 2019. Available: https:// www.sundhed.dk/content/cms/69/4669_dap_aarsrapport-2019_tiloffentliggoerelse_24062020.pdf [Accessed 18 Dec 2020].

3 Rabanal KS, Selmer RM, Igland J, et al. Ethnic inequalities in acute myocardial infarction and stroke rates in Norway 19942009: a nationwide cohort study (CVDNOR). BMC Public Health 2015;15:1073.

4 Agyemang C, Vaartjes I, Bots ML, et al. Risk of death after first admission for cardiovascular diseases by country of birth in the Netherlands: a nationwide record-linked retrospective cohort study. Heart 2009;95:747-53.

5 Agyemang C, van Oeffelen AAM, Norredam M, et al. Ethnic disparities in ischemic stroke, intracerebral hemorrhage, and 
subarachnoid hemorrhage incidence in the Netherlands. Stroke 2014:45:3236-42.

6 Bhopal RS, Bansal N, Fischbacher CM, et al. Ethnic variations in the incidence and mortality of stroke in the Scottish health and ethnicity linkage study of 4.65 million people. Eur J Prev Cardiol 2012;19:1503-8.

7 Wang Y, Rudd AG, Wolfe CDA. Trends and survival between ethnic groups after stroke: the South London stroke register. Stroke 2013;44:380-7.

8 Harding S, Rosato M, Teyhan A. Trends for coronary heart disease and stroke mortality among migrants in England and Wales, 19792003: slow declines notable for some groups. Heart 2008;94:463-70.

9 Ideta TR, Lim E, Nakagawa K, et al. Racial and ethnic disparities in hospital mortality among ischemic stroke patients in Hawaii. $J$ Stroke Cerebrovasc Dis 2018;27:1458-65.

10 O'Donnell MJ, Chin SL, Rangarajan S, et al. Global and regional effects of potentially modifiable risk factors associated with acute stroke in 32 countries (INTERSTROKE): a case-control study. Lancet 2016;388:761-75.

11 Global Burden of Metabolic Risk Factors for Chronic Diseases Collaboration (BMI Mediated Effects), Lu Y, Hajifathalian K, et al. Metabolic mediators of the effects of body-mass index, overweight, and obesity on coronary heart disease and stroke: a pooled analysis of 97 prospective cohorts with 1.8 million participants. Lancet 2014;383:970-83.

12 Andersen GS, Kamper-Jørgensen Z, Carstensen B, et al. Diabetes among migrants in Denmark: incidence, mortality, and prevalence based on a longitudinal register study of the entire Danish population. Diabetes Res Clin Pract 2016;122:9-16.

13 Quiñones AR, Botoseneanu A, Markwardt S, et al. Racial/ Ethnic differences in multimorbidity development and chronic disease accumulation for middle-aged adults. PLoS One 2019;14:e0218462.

14 Brathwaite R, Smeeth L, Addo J, et al. Ethnic differences in current smoking and former smoking in the Netherlands and the contribution of socioeconomic factors: a cross-sectional analysis of the HELIUS study. BMJ Open 2017;7:e016041.

15 Morris AA, Ko Y-A, Hutcheson SH, et al. Race/Ethnic and sex differences in the association of atherosclerotic cardiovascular disease risk and healthy lifestyle behaviors. J Am Heart Assoc 2018;7:e008250.

16 Agyemang $C$, van Oeffelen AA, Norredam M, et al. Socioeconomic inequalities in stroke incidence among migrant groups: analysis of nationwide data. Stroke 2014;45:2397-403.

17 Johnsen SP, Ingeman A, Hundborg HH, et al. The Danish stroke Registry. Clin Epidemiol 2016;8:697-702.

18 Statistics Denmark. Immigrants and descendants, 2017. Available: https://www.dst.dk/en/Statistik/dokumentation/documentationofs tatistics/immigrants-and-descendants/statistical-presentation [Accessed 29 Dec 2020].

19 Statistics Denmark. Data confidentiality policy, 2017. Available: https://www.dst.dk/en/OmDS/lovgivning [Accessed 29 Dec 2020].
20 WHO. Body mass index - BMI. Available: https://www.euro.who. int/en/health-topics/disease-prevention/nutrition/a-healthy-lifestyle/ body-mass-index-bmi [Accessed 29 Dec 2020].

21 von Weitzel-Mudersbach P, Andersen G, Hundborg HH, et al. Transient ischemic attack and minor stroke are the most common manifestations of acute cerebrovascular disease: a prospective, population-based study--the Aarhus TIA study. Neuroepidemiology 2013;40:50-5.

22 Cancelli I, Janes F, Gigli GL, et al. Incidence of transient ischemic attack and early stroke risk: validation of the ABCD2 score in an Italian population-based study. Stroke 2011;42:2751-7

23 GBD 2016 Neurology Collaborators. Global, regional, and national burden of neurological disorders, 1990-2016: a systematic analysis for the global burden of disease study 2016. Lancet Neurol 2019:18:459-80.

24 Markus HS, Khan U, Birns J, et al. Differences in stroke subtypes between black and white patients with stroke: the South London ethnicity and stroke study. Circulation 2007:116:2157-64.

25 Song S, Liang L, Fonarow GC, et al. Comparison of clinical care and in-hospital outcomes of Asian American and white patients with acute ischemic stroke. JAMA Neurol 2019;76:430-9.

26 Frederiksen HW, Zwisler A-D, Johnsen SP, et al. Differences in initiation and discontinuation of preventive medications and use of non-pharmacological interventions after acute coronary syndrome among migrants and Danish-born. Eur Heart $J$ 2018;39:2356-64.

27 Glymour MM, Yen JJ, Kosheleva A, et al. Elevated depressive symptoms and incident stroke in Hispanic, African-American, and white older Americans. J Behav Med 2012;35:211-20.

28 Henderson KM, Clark CJ, Lewis TT, et al. Psychosocial distress and stroke risk in older adults. Stroke 2013;44:367-72.

29 Gall SL, Tran PL, Martin K, et al. Sex differences in long-term outcomes after stroke. Stroke 2012;43:1982-7.

30 Guillot M, Khlat M, Elo I, et al. Understanding age variations in the migrant mortality advantage: an international comparative perspective. PLoS One 2018;13:e0199669.

31 Wallace M, Khlat M, Guillot M. Mortality advantage among migrants according to duration of stay in France, 2004-2014. BMC Public Health 2019;19:327.

32 Wildenschild C, Mehnert F, Thomsen RW, et al. Registration of acute stroke: validity in the Danish stroke Registry and the Danish national Registry of patients. Clin Epidemiol 2014:6:27-36.

33 Hald SM, Kring Sloth C, Hey SM, et al. Intracerebral hemorrhage: positive predictive value of diagnosis codes in two nationwide Danish registries. Clin Epidemiol 2018;10:941-8.

34 Schmidt M, Schmidt SAJ, Sandegaard JL, et al. The Danish national patient registry: a review of content, data quality, and research potential. Clin Epidemiol 2015;7:449-90.

35 Dombrowski SU, Mackintosh JE, Sniehotta FF, et al. The impact of the UK 'Act FAST' stroke awareness campaign: content analysis of patients, witness and primary care clinicians' perceptions. BMC Public Health 2013;13:915. 